\title{
An exploration of the challenge's fathers' experience when parenting a child that presents with dyspraxia
}

\author{
Kyle Jackson \\ Department of Psychology, University of the Western Cape, \\ Cape Town, South Africa, and \\ Michelle Andipatin \\ University of the Western Cape, Cape Town, South Africa
}

Dyspraxia and the challenges faced by fathers

\begin{abstract}
Purpose - Due to the limited research on fatherhood and dyspraxia, this study is critical as it highlights the challenges that fathers face in parenting a child that presents with dyspraxia. The purpose of this study is to inform various interventions while simultaneously highlighting a largely neglected area of research.

Design/methodology/approach - The principal aim of this study was to explore the subjective challenges that fathers experience in parenting a child that presents with dyspraxia in the Cape Metropole area. This study adopted a qualitative approach utilising an exploratory design to understand and provide in-depth information about fathers' subjective experiences of parenting a child that presents with dyspraxia (Mack et al.,2005). Data were collected using semi-structured individual interviews with fathers.

Findings - The authors' findings highlight that fathers' roles are inextricably more complex, shifting between more traditional conceptions such as the provider toward the all giving and nurturing care. Future research would benefit from adopting a more masculinity-focused framework to determine the effect that learning disorders have on constructing and challenging more traditional gendered constructions of what it means to be a man, masculinity and what it means to be a father, fatherhood and fathering.

Research limitations/implications - The study was limited to the challenges faced by fathers whose children were engaged in some or other treatment plan. In addition, the study was limited to children who presented with dyspraxia, rather than those who had received an official diagnosis and this relates directly to the obscurity and ambiguity surrounding diagnosis of the disorder itself.

Practical implications - The study has shed light in terms of the common features between dyspraxia and that of other developmental disorders. This is further extended to include the comorbidity of this disorder with other learning disabilities.

Social implications - Mental health professionals may benefit from identifying the issues raised by fathers within this study and to further aid and support both children and parents in the treatment of dyspraxia.

Originality/value - The study has shed much needed light on two very neglected areas - the area of learning disabilities, in particular, the issue of dyspraxia and second, including fathers' voices in the discussion of their experiences.
\end{abstract}

Keywords Masculinity, Fatherhood, Challenges, Dyspraxia, Qualitative, South Africa

Paper type Research paper

\section{Introduction}

The transition into parenthood may prove to be a difficult and arduous process for most couples. During this period, some couples tend to be vulnerable, while others appear to be resilient (Briesmeister and Shaefer, 2007). It is noteworthy that when couples experience stress, as in the transition into parenthood, "marital friendship" may act as a significant buffer; notwithstanding the quality of this friendship may aggravate the levels of stress experienced

The authors would like to thank the fathers who took part in the study who openly and bravely expressed their experiences of parenting a child that presents with dyspraxia.
Received 1 September 2020 Revised 3 January 2021 Accepted 3 January 2021

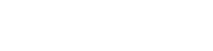


by each prospecting parent (Walsh, 2012). Arguably, women tend to be more vulnerable to experiencing continued dissatisfaction in a marriage, as she is traditionally expected to innately "know" how to be a good mother and to bear the bulk of childrearing responsibilities (Rubin and Chung, 2006). Factors such as dissatisfaction within the marriage, feelings of negativity toward one's spouse and chaos in the lives of the couple demonstrate the precariousness of the relationship leading to an overload of detrimentally problematic stressors (Briesmeister and Shaefer, 2007). Contrastingly, qualities such as admiration, fondness and awareness have been regarded as buffers that protect the relationship during stressful changes (Walsh, 2012). Contrastingly, the role of fathers is often overlooked or ignored, which inadvertently discounts the benefits of an involved father as it relates to child development (Ingber and Most, 2012; Lamb, 2004; Rosenberg and Wilcox, 2006).

In terms of childhood disability, most families are able to adapt and cope effectively. On the one hand, parents may experience feelings of anxiety and some "mild" or transitional depression can be expected; however, through support and attention to prospective problems, most are able to come to terms with their circumstances. On the other hand, some families do not emerge unscathed from such an experience and undergo significant hardships in their efforts to cope. Relatedly, this scenario refers to an important concept, namely, "family resilience" which refers to the likelihood of repair, recovery and growth when families face serious life challenges. In some cases, families are shattered when faced with a crisis event, persistent hardships, disruptive transitions, while others tend to emerge as strengthened and more resourceful (Walsh, 2012). The concept of resilience seeks to explain the ability of some to withstand and rebound from disruptive challenges. Within the context of significant adversity, through a dynamic process, resilience can foster positive adaption, allowing some to be able to cope with a disruptive event (Patterson, 2002). The initial shock of a childhood disability may serve as a challenge that may disrupt family members' perspectives and outlook, redefines goals, strengthens family relations or subverts roles within the family. Resilience may enable the opportunity for family members to reappraise priorities which subsequently leads to more fulfilling lives and compelling relationships (Seligman and Darling, 2007).

This paper seeks to highlight the challenges that fathers experienced in raising a child that presents with dyspraxia. In particular, this paper examines literacy concerning dyspraxia, fathers' sense of helplessness, various circumscribed interactions, school's acquiescence of children presenting with dyspraxia and the general lack of support. It is therefore argued that having a child that presents with dyspraxia is met with a number of multifaceted challenges experienced within the child themselves, the entire family unit, various health professionals and the broader socioeconomic environment within which the family unit exists.

\section{Background}

\section{Parental experiences of raising a child with a disorder}

The implications of one's child receiving a diagnosis may be vast and triadic. The first of which is the experience of dysfunction felt by the child him/herself, the family that has been affected and the larger external environment within which the disability has manifested. The realisation that one's child may have a developmental disability may be regarded as a crisis and one of the most difficult experiences for any parent (Heiman, 2002). Families of a child with a developmental disorder are vulnerable to high levels of stress and ongoing challenges. In addition, research on families has primarily focused on mothers rather than on fathers, highlighting the importance of the current study (Al-Yagon, 2015).

The initial reactions experienced by most parents have been linked to that of bereavement and therefore, tends to be perceived negatively. However, families process and react differently either by adapting more flexibly and mobilising into action or some may resist or deny the actual diagnosis, freeze or become rigid and thereby ineffective in their approach (Poslawsky et al., 2014). Disruptions in daily routines are often experienced in families with a child 
diagnosed with a particular learning disability. These routines are essential to providing care for a child and perhaps as a reaction to being unable to instil routine, parents respond with anxiety, rigidity and overprotection in their childrearing capacities (Jones and Passey, 2004). This results in a greater emphasis on maintaining a sense of control as opposed to highlighting the possibility of personal growth and development. Subsequently many parents of children with disabilities are more prone to developing health related issues, greater levels of depression and feelings of being restricted and confined (Heiman, 2002).

Considering much of the available literature, a number of studies have examined the similarities and differences of experiences amongst mothers and fathers of children with a disability (Kersh et al., 2006). It is typically reported that mothers described greater stress than fathers, while many studies report that there is no difference in this regard. In addition, mothers and fathers report that various combinations of stressors/variables may contribute to their perceived levels of stress differently (Yamada et al., 2012). Finally, fathers tend to be less involved in the day-to-day care of their child than mothers irrespective of whether she is fully employed (Kersh et al., 2006). Moreover, it has been argued that the behavioural difficulties of children experienced by parents serve as a stronger predictor of stress than the severity of the child's disability itself (Hastings, 2003).

According to Freedman and Boyer (2000), families supporting individuals with developmental disabilities experience a number of difficulties in terms of their financial obligations, the perceived lack of coordination amongst various authorised personnel, departments or agencies as well as exiguous and insufficient support. Parents of children with disabilities are often concerned about their child's future and their ability to function in environments that may not be sheltered or are less restrictive. These families therefore face both the "normal" tensions and pressures of life having to adjust to having a child with a disability and therefore, often require assistance to positively adjust their lives (Heiman, 2002).

More notably, families that have transitioned to having a child with a disability experience various changes within their social lives. This is further exacerbated by feelings of anger, shock, considerable stress, denial, self-blame and guilt (Heiman, 2002). Different avenues of assistance that parents often look to are various support groups, educational advisors, psychiatric consultations, psychological services, voluntary organisations or special education systems (Henninger and Taylor, 2014).

\section{Fathers}

Marsiglio 2008 (as cited in Mavungu, 2013) asserted that the practice of fatherhood is contingent on three varying dimensions; the first of which examines paternal motivation, followed by paternal involvement and concludes with paternal influence. Paternal motivation is concerned with the various reasons why men would want to play an active role in the lives of their children. Although not limited to, some of these reasons emanate from the love that men have for their children, based on early experiences within their own families, various social pressures to act as masculine adult males, as well as the perceptions that their children either need financial resources from them or their involvement (Masiglio, 2008). The second dimension proposed by Marsiglio 2008 (as cited in Mavungu, 2013) seeks to explain paternal involvement as a dimension within the practice of fatherhood. Aspects of accessibility, cognitive representations, responsibility and engagement comprise the dimension of paternal involvement. In this instance, cognitive representations allude to different states of mind such as worry, anxiety and contingency planning related to the well-being of the child. Responsibility on the other hand refers to the sense of duty assumed by the father in terms of their child's well-being, and engagement refers to the direct interactions between a father and his child (Masiglio, 2008). The final aspect to consider in terms of the practice of fatherhood is the influence that they exert on the lives of their children. This dimension is encompassed by
Dyspraxia and the challenges faced by fathers 
four general principles such as the nurturance and provision of care offered by a father, the emotional, psychological and practical support he offers to his partner, economic provision and finally the ethical and moral guidance he offers. These four principles are closely linked to the well-being of children and their development (Masiglio, 2008).

An often-understated role of the father is usually presented, however; the role of a father has been found to influence a variety of aspects, especially in terms of the family unit and in child rearing (MenCare: A Global Fatherhood Campaign, 2012). Fathers that assume greater roles in their child's lives tend to work fewer hours, have greater psychological adjustment characteristics such as a higher self-esteem, lower levels of depression and aggression and their wives reported greater marital intimacy as well. In addition to this, benefits for the child include a greater level of empathy, less behavioural problems, lower levels of substance abuse and greater social, emotional and cognitive development (American Psychiatric Association, 2013). Fathers tend to be more involved in physical activities with their children and are therefore exposed to a large precursor for the early warning signs of dyspraxia, a disorder of a child's fine and gross motor skills (Lavoie, 2001).

In a study conducted by Mavungu (2013), men considered their role and sense of masculinity in terms of their ability to provide material goods or finances to their families. Consequently, fathers' distance themselves from care-giving which was initially seen as a woman's responsibility. What is also evident is that father absence in their own lives contributed to them being an absent father which seems to point to the generational transfer of fathering models. Through this assertion fathers' distance themselves from the care-giver role which was ultimately seen as the responsibility of the mother. In addition, a number of fathers who were absent in the lives of their own children experienced absenteeism of their own fathers. This alludes to the transmission of father models across generations linking to the possibility of a vicious cycle surrounding the absence of fathers. Finally, the concept of fatherhood is strongly linked to employment and in a country where unemployment is rife; a father who is unable to provide for his family will feel emasculated and unable to assume the status of fatherhood (Mavungu, 2013).

\section{Dyspraxia}

It is important to state from the outset that the concept of dyspraxia is met with various contestations and a number of experts within the health professions, in academia and by extension parents as well, therefore use the word interchangeably. The definition of dyspraxia has varied greatly within the literature often as a result of the professional standpoint or disciplines of the authors themselves (educators, neurologists, occupational therapists, psychologists, etc.) subsequently leading to a greater sense of confusion (Steinman et al., 2010).

The construct of dyspraxia has been shrouded in a variety of definitions from various fields of study. Put simply, the disorder has been described to refer to abnormal motor behaviours or difficulties experienced with regards to motor movements (Tanaka et al., 1996). More aptly, the disorder has been described as difficulties associated with motor movements that are exacerbated by various perceptual difficulties. In addition, dyspraxia is considered to refer to impairment in or difficulty associated with planning, organising and executing various physical movements. The disorder is subsequently considered to be developmental in its origin as opposed to a disorder that is acquired (Gibbs et al., 2007).

Previously, the concept of developmental coordination disorders (DCD) and dyspraxia have been used interchangeably and mistakenly so. The concept of DCD was rather understood by many to refer to a range of disorders involving coordination difficulties of which dyspraxia was one (Peters et al., 2001). Further to this, DCD was used to refer to a range of disorders that are fundamentally developmental in nature, and therefore, its definition has been closely linked to dyspraxia. Dyspraxia, however, was referred to as the impairment in 
organising various motor movements and in some cases perception, language and thought processes as well (Steinman et al., 2010). Key to this point is the recognition that dyspraxia is not the result of cognitive impairments but rather the inability to process and organise incoming information from one's external environment (McMurray et al., 2009). The prevalence of $\mathrm{DCD}$ varies from one country to the next; however, it is estimated that approximately $5-6 \%$ of children aged between 5 and 12 years of age meet the diagnostic criteria for DCD (Santrock, 2014).

The family in its entirety can be affected by having a child that has been diagnosed with dyspraxia. In a study exploring the social impact of living with dyspraxia researchers found that in many cases mothers would tend to be more informed about dyspraxia and were able to answer many of the questions that they were asked relating to the disorder (Payne et al., 2013). In many cases though, fathers were unable to understand what was happening with their children and the unique challenges that they faced. As such, fathers were less tolerant, perhaps owing to a sense of powerlessness, which would result in tension between both parents; however, in some cases, children expressed that their fathers were positive role models in providing support and understanding (Payne et al., 2013).

\section{Theoretical framework}

Bowen's Family Systems Theory and the Family Resilience Framework were used to guide the current study.

According to Smith-Acuna (2011), family systems theory provides a framework in which families construct past and future experiences through communication and dialogue. Family systems theory suggests that families should be considered as systems which serve as interacting and reacting parts functioning as a reciprocally influencing unit (Bregman and White, 2011). These individual parts function with their own interrelated elements and objectives demonstrating clear behaviours, engaging in regular interactions and further exist interdependently of one another (Haefner, 2014). Each family member is considered one of the interrelated elements that exist and co-construct the family structure and environment (Berryhill et al., 2016).

In terms of how families are able to respond to adversity and their ability to heal, grow and recuperate refers to a family's sense of resilience (Becvar, 2013). The family resilience framework suggests that as challenges and crises arise, the impact is felt by all members of the family unit, and therefore, there are a number of subsequent processes that mitigate recovery of not only the individual elements but also their relationships as well (Saltzman et al., 2013). Furthermore, the framework extends to examining the various communications and organising patterns within the family unit.

Theoretically, the correlative function of the family systems theory and the family resilience framework allows for an in-depth analysis in terms of how fathers interact with all the interdependent elements of the family system and how these elements affect him in turn. In addition, the family resilience framework delineates how fathers adapt and ultimately cope with parenting a child with a disability (Baum, 2007; Haydon-Laurelut, 2011; Kaur and Scior, 2009).

In light of the above, and due to the limited research on fatherhood and dyspraxia, this study is critical as it highlights the challenges that fathers face in parenting a child that presents with dyspraxia that may inform various interventions while simultaneously highlighting a largely neglected area of research.

\section{Method}

Research design

The principal aim of this study was to explore the subjective challenges that fathers experience in parenting a child that presents with dyspraxia in the Cape Metropole area. This
Dyspraxia and the challenges faced by fathers

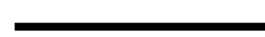


study adopted a qualitative approach utilising an exploratory design to understand and provide in-depth information about fathers' subjective experiences of parenting a child that presents with dyspraxia (Mack et al., 2005). Data were collected using semi-structured individual interviews with fathers.

\section{Research context}

The current study was conducted in the Cape Metropole area, in the Western Cape, South Africa. The final sample consisted of 14 fathers who ranged from the following widespread suburbs: Belhar; Bellville; Bonteheuwel; Boston; Durbanville; Paarl; Parow and Table View. These suburbs vary in terms of geographical space and socio-economic status ranging from more affluent to lower-income, resource constrained communities.

\section{Participants and sampling}

A non-probability sampling method was employed, as fathers were selected based on whether they possessed specific qualities or experiences necessary for the current study (Terre Blanche et al., 2011). The study was limited to fathers that demonstrated presence and involvement in their child's life. An expert within the area of dyspraxia purposefully selected fathers based on these criteria. Fathers were selected from various non-profit organisations, schools and centres that specifically focus on children with learning difficulties. Parents were informed of the nature of the current study and those that indicated a willingness to participate provided their contact information.

Typically, dyspraxia is present with a number of co-morbid disorders and together with the lack of clarity surrounding the disorder's definition (Colley, 2006; Gibbs et al., 2007; Jongmans et al., 2003; Miyahara and Baxter, 2011; Peters et al., 2001; Steinman et al., 2010; Zwicker et al., 2012), a diagnosis is problematic. As such not all children within the study strictly aligned to the DSM-V criteria for dyspraxia but rather in terms of how the children presented with the disorder.

In total 14 fathers were individually interviewed. In line with the criteria outlined by Malterud et al. (2016), the sample size for the current study is considered appropriate as it relates to the concept of "information power". According to the five steps provided and owing to the nature of the present study, the contribution of knowledge to a gap in the literature surrounding dyspraxia and fathers' perceptions of parenting, a smaller sample size is required to produce sufficient information power. Instead, given the specificity of the current study's aim, weight is rather placed on the depth of information (Malterud et al., 2016).

Owing to apartheid policies and forced migration, families in South Africa experience large discrepancies in socio-economic status, and therefore, the country is regarded as one of the most unequal countries in the world particularly in terms of social and income inequality (Botha et al., 2017). As such, a diversified sample of fathers in terms of age, race, culture and income was required. Fathers had a mean age of 41, and eight identified themselves as "white", five identified as "coloured" and one identified as "Indian". The participants also differed in terms of marital status with most indicating that they were married $(86 \%)$ and the remaining were divorced (14\%). Only one father in the study had a daughter, while the other thirteen fathers had sons. Fathers also differed in terms of their educational backgrounds ranging from matric (grade 12) to various tertiary degrees.

\section{Data collection}

Ethics clearance was obtained from the Senate and Ethics Research committees of the University of the Western Cape. Thereafter, recruitment, gaining of informed consent and the interview process took place. Each of the 14 semi-structured interviews was guided by an interview schedule that was informed by the recommendations and suggestions from various 
literary articles, as well as the theoretical position of the current study. Each interview ranged between 45 and $75 \mathrm{~min}$ and the discussions therein developed organically from the abovementioned interview schedule. Examples of some of the questions were: "what are some of the challenges you face with your child?"; "as a father what are some of the challenges that you experience in parenting a child that presents with dyspraxia?" etc. A pilot run was also conducted to ensure that the interview schedule was appropriate in terms of the language used and effective in addressing the specific objectives of the current study. None of the participants who participated in the pilot run took part in the main study. It was imperative to ensure that a debriefing session took place after each interview which provided an open dialogue to impart knowledge about father's experiences, attitudes and beliefs regarding the research process and to clarify their emotional expression of the experiences shared (Houghton et al., 2013). The debriefing session allowed the main author to identify any participant who may have been adversely affected by the research study and to offer psychological support and appropriate referrals. Although referral was emphasised, all participants refused the offer.

\section{Data analysis}

The data were collected and analysed simultaneously to allow for the analysis to unfold inductively rather than deductively as data collection took place (Visagie, 2010). Each interview was analysed using Clarke and Braun's (2013) six-phase guide to conducting a thematic analysis. Phase one included familiarising ourselves with the data which was characterised by reading and re-reading the transcripts, in all cases together with the audiorecordings. Phase two encompassed generating initial codes by grouping similar ideas together. Once this had been completed, an external reviewer, a $\mathrm{PhD}$ candidate in Psychology reviewed the initial codes and corresponding excerpts to confirm eligibility of the identified codes and to minimise bias on behalf of the researcher. Phase three aimed to identify themes based on the initial codes, whereas phase four aimed to review and refine these themes. In phase five each theme, was defined and named with the assistance of a second external reviewer with a $\mathrm{PhD}$ in psychology. Phase six of the analysis produced the thematic domains, themes and sub-themes of the study. Each transcript was read and re-read, which culminated into 17 broadly defined codes. A data extraction table was used in order to manage and guide the process of coding and also assisted in grouping the 17 codes into 5 themes which were encapsulated into the overarching thematic domain of "challenges". The coding and grouping of codes into themes were verified by three additional psychology researchers. The mechanisms employed to ensure the credibility and trustworthiness of the study were peerdebriefing $(\mathrm{PhD}$ and $\mathrm{PhD}$ candidate in Psychology), all decisions and processed followed were documented in detail using an audit trail and providing a thick, rich description (describing the setting, participants and themes in detail) (Terre Blanche et al., 2011).

\section{Procedure and ethics}

Participants who expressed interest in taking part in the study were contacted through email, text-message or a telephonic call in order to discuss the nature of the study and what would be expected from the participants should they agree to take part, dates, venues and times to conduct the individual interviews that was convenient for each participant. Each venue was discussed separately and therefore, ranged between various coffee shops, restaurants, home and employment environments.

Upon establishing a sense of rapport, each participant was provided with an information sheet comprising of the nature and details of the study. This included the purpose of the study and the rights of the participant. Anonymity and confidentiality were discussed with each participant.
Dyspraxia and the challenges faced by fathers

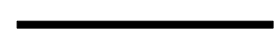


Each participant was asked to provide signed consent indicating that they agreed to voluntarily take part in the study, that they understood what the study entailed, their rights as participants and how the findings of the study would be used. Each interview was conducted by the primary author.

\section{Results}

\section{Challenges}

This domain encompasses the challenges faced by fathers in parenting a child that presents with dyspraxia. The key themes that enclose this thematic domain were health literacy; helplessness; circumscribed interactions; schools' acquiescence and lack of support. These themes will be further presented and elaborated on below.

\section{Health literacy}

The first theme refers to the difficulties associated with understanding dyspraxia and the implications thereof. This may be related to the fact that many of the concepts surrounding the disorder are synonymous or have been used interchangeably (Zwicker et al., 2012). This was demonstrated by one participant where he (Participant 1, p. 1) states that "one of the first things that we found out was that dyspraxia is one of those things that not a lot of people know about um schools have not even started mentioning dyspraxia, like what the hell is that, nobody knows or has heard about it um they do not know what to do with the disorder but then we also found out that there is quite significant difference in the levels of dyspraxia and the different kinds of dyspraxia that you find". Disorders such as dyslexia, ADHD (attention deficit hyperactivity disorder), OCD (obsessive compulsive disorder) etc. are more commonly known, especially outside of the health professions.

This is confirmed by Steinman et al. (2010), who emphasise that the term dyspraxia is open to debate and is used interchangeably with multiple terms depending on the discipline of the consulting professional. Furthermore, early intervention is paramount with regards to dyspraxia, and therefore, schools need to be acutely aware of the nature of the disorder to be able to make the appropriate referrals where necessary (Steinman et al., 2010). In addition to this, it was found that approximately $91 \%$ of physicians were unaware of developmental coordination disorder, a term incorrectly used synonymously with dyspraxia (Gaines et al., 2008).

Resultantly, because not much is known about the disorder as a whole, a number of interventions that have been tailored to each child seem to yield the greatest impact on children that present with the disorder. In turn parents and professionals involved are not always able to definitively identify which method being used has had the greatest influence. This was described best by one father (Participant 3, p. 6) when he stated that "the biggest challenge for me is trying a whole lot of things, like speech therapy, O.T (Occupational Therapy) everything you name it to doctor, and doctors prescribe this and Ritalin and a whole lot of things that I am not even familiar with and then you see improvement in your child, but to me I can't pinpoint what is actually created the improvement, is it O.T, is it speech, is it the tablet that he is on, is it us or the things we are doing at home and that to me is basically what is challenging.

Parents of a child with a learning disability are often consumed by the various therapeutic interventions tailored for their child and are often forced to assume part-time work or become a stay-at-home parent (usually the mother) (Novak et al., 2011). This can have a debilitating impact on the financial standing of the family. Mavungu (2013) states that male participants in his study revealed that they place significant importance in their ability to provide material goods and finances to their families. With the added financial pressures associated with a child that has a learning disorder together with the critical rates of unemployment in South 
Africa, an unemployed father may be unable to provide for his family, feel emasculated and therefore, unable to assume the status of a father (Mavungu, 2013). Subsequently, a father may withdraw from his responsibilities within the family, adding greater pressure onto other members to fulfil his role and thereby places the entire unit into disarray.

In addition, a particular challenge highlighted by fathers relates to the influence of family which seemed to add to the confusion experienced. This was described by one father (Participant 5, p. 7) "I mean people always like to give advice, like what to do, what not to do with the children ... but when you have this kind of issue they do not have that kind of experience to give so they are not qualified to make that call yet um the struggle is trying to get that across and not seem ungrateful or whatever".

Parents often spend an extortionate amount of time providing knowledge and support to others, rather than maintaining their focus on the needs of their child. Parents may experience a great sense of pressure from family members who offer guidance incorrectly and a greater need to convince others of the nature of the disorder itself. The juxtaposition of having to provide others with knowledge and support when the parents themselves need support is therefore apparent and as such a greater emphasis is placed on the resilience of each parent.

\section{Helplessness}

The succeeding theme to be discussed is the sense of helplessness that fathers experienced in parenting a child that presents with dyspraxia. This was further described by one father (Participant 5, p. 2) who emphasised that the struggle with the "smaller things" such as getting your child to simply eat their breakfast can be difficult and timeous. Ultimately you become late for work and subsequently your employer may not always understand your reasoning. This inadvertently places parents, particularly fathers in this case, in a position where they experience a sense of helplessness in the struggles of daily life.

This can further be demonstrated by another participant (Participant 8, p. 3) where he describes that as a parent "sometimes we sit back and think ay, this guy is just being naughty his pushing his luck but I think its fine line and then obviously you as a person get frustrated coz I mean there are times when you feel a bit frustrated with him when he is not doing something the way that he should be doing but then there is also times that you over compensate you give him favouring you know, so as a parent that's the juggling act we doing every day from getting him dressed to trying to give him medicine you know".

Traditional conceptualisations of fatherhood suggest that the father is the one responsible for the discipline of his child. A father may experience a greater sense of difficulty between making the distinction between misbehaving and the effects of the disorder itself (Masiglio, 2008).

In addition to this, fathers described their sense of helplessness as an intrinsic process of denial. This was described more appropriately by one father (Participant 5, p. 6) where he alludes that as a parent you "mask it you know and that is unwilling you know their own brain says that he has made some kind of milestone there so you think it can't be that you know and until you actually get the assessment and you get all the information in front of you, then you can see for yourself ok this is the case, this is what we are dealing with here". This sense of denial can be debilitating for some parents, especially when there is a lack of support. However, in some cases where parents have adopted alternative methods of support, they seem to manage the sense of helplessness better. This was explained by another father (Participant 10, p. 8) where he describes that "yeah it was obviously hard to hear that there was something wrong with your child but once we researched and understood what it was about it was actually a bit of a relief that we actually know what is going on, we know that it can be um I do not want to say that it can be cured obviously you know but it can be managed to a certain extent um and now we know that
Dyspraxia and the challenges faced by fathers

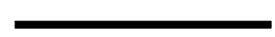


at least now he needs some extra attention. He needs to maybe work a bit harder and um to be able to do what other kids are able to do um and at least now we can assist him to do".

Moreover, fathers experienced a sense of helplessness in terms of the financial implications of having a child that presents with dyspraxia. In some instances, families are limited in that they may not be able to afford medical insurance. Also, some families are unable to claim for certain therapies (occupational therapy, speech therapy) which can impair the treatment options available for children that present with dyspraxia (Participant 5, p. 11). The costs involved can be devastating for families, especially where there is more than one child to care for. This was emphasised by one father by stating that his child that presents with dyspraxia costs him approximately as much as what his other four children cost per month (Participant 7, p. 1). As a parent, perhaps more, especially as a father where traditionally his role is to provide financially, this burden can be difficult to accept (Neale and Davies, 2016). As a father, he may experience a greater sense of helplessness because he is unable to provide for his child as well as for the treatment that they may require as a result of the disorder itself.

As described by Masiglio (2008), a father's sense of masculinity rests upon his paternal motivation (reasons why he plays an active role in his child's life), involvement (worry and anxiety associated with the well-being of his child, responsibility towards the well-being of his child and his direct interactions with his child) and influence (nurturing and care, emotional, psychological and practical support for his family, economic provision and ethical and moral guidance offered). However, when a child is born with a disability a parent must renegotiate all previous knowledge associated with parenting (Novak et al., 2011). The ability of the father to self-differentiate is therefore contingent on how he is able to adapt and cope with the diagnosis of his child, and thereby re-establish homeostasis within the family unit (Titelman, 2014).

\section{Circumscribed interactions}

The third theme that falls within the challenges thematic domain refers to the various constrained interactions experienced by fathers between fathers, between children, spouses and more broadly institutions and organisations.

This has been demonstrated by one participant (Participant 5, p. 1) when stating that "interlinked but that has been one of the challenges in having to deal with your child, when they can't verbally communicate or even physically communicate um with you and the level of frustration just rises in both parent and child so you have um that to contend with, you got from a disciplinary standpoint as well is also very very difficult". Perhaps stated more explicitly another participant (Participant 3, p. 9) stated that "you know I think to myself you know like what is he going through if I am getting frustrated and I can't understand him, how much more frustrated is he getting that he can't convey the message over to me you know".

The challenge of being unable to communicate with your child has various implications for your role as a parent. This was further described by one father where (Participant 8, p. 2) "you know from the age four, he was saying things like he is gooing [throwing] a tantrum. You not sure as a father, you do not, is this now, is this now a naughty boy? Must you uhm, must you give him some of the belt? Which we've never done but Imean you know sometimes you feel like it so that's some of the frustrations as a parent also is that uhm you know is the child naughty then you actually find out this guy's not actually naughty he just, he just can't express himself. So then I thought about it, I told a, I told a colleague of mine at work, imagine walking around with a piece of tape around your mouth whole day and you want things and you can tell nobody and I said that's exactly how my son feels so that's why we doing something about it".

Consequently, many fathers reported that they experienced a mismatch between what they expected and what actually transpired. This was described by one father (Participant 9, 
p. 4) in terms of teaching his child, which forms an integral component of basic family building blocks (Xu, 2019). According to one father, the aspect of teaching as a parent must be met with a sense of "patience is the biggest virtue, you have got no choice you know in 2 years of speech therapy, after 2 years of speech therapy he still can't formulate a sentence so we still can't have a conversation. After 2 years of speech therapy he still can't understand the concept of question and answer".

The excerpt points to the frustration felt, as his child is still unable to communicate even after extensive speech therapy. This inability to communicate hampers the interactions between the father and his child. Communication forms the basis of many interactions including, but not limited to aspects such as nurturing, setting limits and boundaries, discipline and providing guidance (Strong et al., 2011). Given the challenges surrounding communication conflict not only between father and child but also siblings and spouses may be a real consequence. Communication processes are essential in establishing resilience within the family unit, however coupled with rising levels of frustration may unravel previous states of homeostasis. This disruption thereby affects the family unit's ability to function effectively (Walsh, 2016).

Fathers also described experiencing challenges within their spousal interactions. This was demonstrated by one father (Participant 5, p. 16) as something that "ranks up there as one of the top 3 challenges, is just trying to keep your sanity with your spouse while you are having to deal with all of this um I mean you take all the things that come with marriage and kids and now you add this into the mix. . good communication I think is the main key and if things go south or whatever get help as quick as you can because we've seen a lot of, and even at the school as well, we've seen a lot of cases where divorce is high and it is just bad you know and it is really bad for kids to come out of broken homes and stuff".

The above extracts indicate the essential role that communication can play within the spousal dyad. In addition, communication may more greatly assist families to avoid disruptive crises that ultimately affect the ability of the family to function effectively. Perhaps more importantly, it is important to note the distinction that exists between communicating with one's child and communicating with one's spouse that is also interrelated and thereby mutually influenced. Experiencing a break-down in communication with one's child may facilitate greater levels of conflict within the parental subsystem as frustration levels increase, thus acting as a potential catalyst for conflict within the spousal dyad. This form of triangling where tension experienced between two members of a family unit is passed onto a third may further serve as a wedge between balancing differentiation of oneself and forging a supportive and encouraging relationship (Smith-Acuna, 2011). Consequently, this snowball effect may disrupt the entire family unit, eventually rupturing the unit's state of homeostasis or equilibrium (O'Gorman, 2012).

The challenges experienced also relates to the ways in which each parent navigate their ways through parenting. This is perhaps more appositely described by another father (Participant 5, p. 1) as allowing his children the freedom that other neuro-typical children experience. This exists as a result of being judged by people, especially as they often remark that "you well why do not you let your kids do more and get to experience a bit more. You can but it has to be within boundaries because you know um of what they are struggling with". The various ways in which one rears a child may cause conflict, especially as parents need to reevaluate their sense of parenting when their child has been diagnosed with a disability (Novak et al., 2011).

Another important point to note on the one hand is the experiences of family in relation to the well-being of the child which was described by one father (Participant 7, p. 4) as "there is some instances where some of the family feel that he is dumb you know that type of thing and they sort of distance themselves from us. [Interrupted by a Phone Call]. We have family members that have sort of distanced themselves from us because um they blamed either myself
Dyspraxia and the challenges faced by fathers

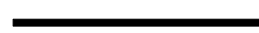


or my wife from both sides of the family that it is our fault that he is the way he is". On the other hand, fathers described the experience where families tend to become overly involved for example, as suggested by a participant (Participant 9, p. 9) "we would hear from family no you all do not talk to him enough, you all do not interact with him enough, take him out more, you do not take him out enough um read to him, you do not read to him enough you know and um do this for him. People coming out with their home based cures you know um and their own personal suggestions and you reach a point where you just say yes to everything because everybody seems to know or thinks that they know best and what to do and how to do it. . . so that pressure from the day that he is born you know to that point from family and I would not say so much friends um but family particularly is quite unbearable because everybody seems to know, to think that they know exactly what is best and they always think the other way around that what you are doing is always wrong you know and therefore the child is um he is not talking or he is struggling with whatever it is so it is almost becoming a reflection of your role as parents".

Friends and family spheres usually serve as significant sources of support and encouragement; however, as noted by a number of fathers, it can be a substantial trigger for stress, pressure and conflict. Social relationships are vitally important in strengthening a family's sense of resilience as well as an individual's state of well-being (Walsh, 2012). Furthermore, the negative perceptions of family members with regards to the ways in which one parents may create greater levels of conflict within the spousal dyad, especially in instances where mothers and fathers disagree on the level of involvement of the family. It is suggested that mothers tend to draw on these external sources of support more than fathers do (Karande and Kuril, 2011).

Finally, owing to possible preconceived ideas or naivety, people outside of the family unit may be prejudiced against children who experience a disability, constraining interactions between not only members within the family unit (such as father and child) but also between the family unit and the external environment. This was described by one father (Participant 7, p. 4) as something that "hurts me, and I have had a lot of fights, one that almost got physical because someone like called him dumb. Um and like I said he is actually highly intelligent um, he can do a lot more on certain things with problem solving that his brother that is 7 now can't do still and he can at the age of 4, he can solve it where the other one gives up too quickly and um so just that disconnect from society still because they see it as a contagious disease um scared that they might catch it".

In addition to managing daily tensions and pressures of life, parents must also contend with the broader social spheres beyond the family unit (Heiman, 2002). In the extract above, a father highlights the ignorance and callous nature demonstrated by others in relation to his child.

\section{Schools acquiescence}

An important challenge that was described by fathers is the acquiescence of schools towards the needs of children that present with dyspraxia and by extension that of the parents as well. One particular father (Participant 3, p. 4) described an experience with a school where his child was to be enrolled. They had hoped that the school would allow his child the opportunity to "familiarise himself and I think it would be very harsh and unfair on us if we had to go to a new place and drop him off there and leave him. I think we would take 5/6 steps if not more backwards in that aspect that's why at some schools we, I would not say the word nasty but we did not feel comfortable in the sense that they were not happy for us to bring the child there before and familiarise himself around, show him the teacher and so on and they did not understand that aspect and that to me was very frightening and wrong because like I said I wanted him to feel comfortable, I wanted him to know ok I am going there, there is nothing wrong with the place". 
This was further demonstrated by another father (Participant 9, p. 3) when exclaiming that "our son has been to two schools where they did not want to accept him because of his tantrums um because we went to one school where he was, um they gave him a place and as we were leaving he slapped me and then the next morning we got an email explaining why they can't give him a place at the school".

The extracts above suggest that institutions within the broader environment are unsympathetic towards the needs of the individual child. This may in-part be due to the fact that many are unaware of dyspraxia and subsequently the various implications of the disorder (Gaines et al., 2008). Consequently, parents are faced with the added pressure of having to inform schools of the nature of dyspraxia. The aspect of feeling supported by schools is critical for parents, especially in institutions that are more acutely focused towards children with special needs and perhaps more broadly the needs of parents as well.

\section{Lack of support}

The final theme that falls within the second thematic domain is the lack of support that fathers experienced One particular father (Participant 9, p. 9) explained the process of asking for support from family as "um yes like we could have made a phone call but whether the understanding was there but um maybe, I am not sure, my wife would have agreed you know on that um whether it was her family or whether it was my family but you could make that phone call but it would most probably turn around and you know to being you know that once again you, you are so we had reached a point eventually where we would just focus on Udeshan and just forget about everybody else so we did not have anybody to lean on. I think that the best form of support that we got was, I will not say the medical practitioners but most of the speech therapists and occupational therapists, people that actually understood the condition but more than understanding the condition, understanding the effects and the impact that the condition has on the family".

The description above illustrates that relying on one's family for support can serve a double-edged sword as parents may be desperate for support and understanding, but may be met with criticism, prejudice and misunderstanding instead. Consequently, families may need to reorganise patterns and place particular boundaries to buffer against the critique of others in an attempt to maintain a sense of resilience (Becvar, 2013). Notwithstanding, parents may experience feelings of isolation, and therefore, various health professionals should be acutely aware that their services and roles encompass more than simply the transfer of knowledge but rather to provide families and perhaps more specifically parents with a sense of support and understanding (Novak et al., 2011).

More broadly, a father (Participant 3, p. 3) described that the lack of support available relates to the lack of resources for children that present with dyspraxia. He emphasises that "maybe in a way if we had picked it up earlier it would not be so bad, he would maybe be more advanced now um and also I think that which I am hoping which is why I am doing anything that can try and help anybody else with dyspraxia or anyone that comes afterwards that has a child with dyspraxia, if I can be able to change the experience that we had in the sense that there is something out there that can give them help because with us there was no place and there still is no real school that can help kids with dyspraxia and that is what I am trying to get out there that if somebody can come up and say listen here, if your child gets diagnosed with dyspraxia or if you are not $100 \%$ sure come to us we can try and help you, see if it is dyspraxia and then maybe we can put you on the right road which can help a lot that's what vision I have".

Although some fathers indicated that they felt a greater level of support from various health professionals, a number of fathers indicated that beyond this, they receive very little to no support from external institutions and organisations. In some cases, parents experience a particular level of indifference from schools in accommodating the various needs of both 
parents and child. Most children are referred for an assessment during their initial years of primary school, perhaps owed to the delay in reaching age appropriate milestones (Steinman et al., 2010). However, this highlights the critical role that teachers and schools can play in aiding the prognosis of a learning disorder and the effectiveness of an early intervention.

\section{Discussion}

This study aimed to elucidate the challenges that fathers' face in parenting a child that presents with dyspraxia. The motivation for this study was the scarcity of the available literature pertaining to the topic of dyspraxia within the South African context and more particularly the inclusion of fathers' subjective experiences. The analysis highlighted the fluidity and complexity involved in the role of a father, as it relates to having a child with a learning disability and the implications thereof on the family unit.

More specifically, participants alluded to the various challenges that they experience when parenting a child that presents with dyspraxia. The first of which surrounded the lack of awareness of the disorder itself and how this related to receiving a diagnosis, the understanding of others (family, friends, health professionals and organisations) as well as the implications of the disorder for the child, the parents and more broadly the family unit. The lack of awareness and information regarding the therapeutic options can have a major impact on the financial stability of the family which in-turn further casts the father into a more traditional provider role. Notwithstanding, the amount of time that parents spend having to explain the nature of the disorder as well as its various implications to others places undue stress and pressure on the father-mother dyad. This is further extended to the acquiescence of schools and the lack of understanding, awareness and knowledge surrounding the disorder which therefore places parents at the forefront of sharing information. Notably this creates added pressure and frustration for parents who already feel insecure as there is very little information to go on in an attempt to find effective treatment options and organisations that are best equipped to assist.

Due to the above-mentioned factors, fathers revealed a sense of helplessness that begins to fester within the family unit. This was experienced when attempting to get their child to engage with the finer things of day-to-day living as well as the amount of time spent (e.g. getting their child ready for school in the morning), which more broadly has various implications for the parent (such as work obligations). Participants also experienced a sense of helplessness when navigating through the issue of discipline as it represents a rather grey area in terms of being able to discern whether their child is being "naughty" or whether a symptom of the disorder is perpetuating a particular unwanted behaviour. A link can be seen to a sense of denial which may further culminate in experiencing total sense of helplessness. This was further extended towards the financial implications of various treatment options needed for their child and the inability to provide financially may result in experiencing feelings of helplessness once again as the father is cast back into the role of the provider.

On the other hand, a child that presents with dyspraxia may experience increased difficulty in communicating effectively. As a result, parents often dedicate a large amount of time, money and resources towards tailoring a therapeutic intervention for their child. However, in many cases, irrespective of the intensity of the therapy a father is unable to communicate with his child which subsequently gives rise to increased levels of frustration.

The added pressures of external family and friends can place unnecessary stress on the lives of the family unit, especially when the family views are in direct opposition to either parent. Communication may therefore assist families fostering a greater sense of resilience by sharing of critical information, providing clarity of differing views, an opportunity for collaborative problem solving and encouraging greater emotional sharing within the dyad (Becvar, 2013).

However, this further illustrates the disconnection between more traditional gendered roles where men are perceived to not communicate and maintain the tough guise, but, in this 
study, fathers have emphasised the importance of communication (Conway, 2008). Moreover, the difficulty experienced in communicating exposes families to unwarranted outside criticism and pressure and labelling of the child by those outside the family unit is usually negative in nature, thereby creating conflict and unnecessary pressure and stress within the family unit.

The lack of support experienced was emphasised by participants, perhaps largely because of the lack of awareness and understanding of the disorder. Participants also emphasised that support serves as a double-edged sword in offering parents a platform to receive assistance but at the same time also being met with criticism, judgement and undue stress and pressure from outsiders. Moreover, participants expressed that they received very little support from external organisations and being unable to obtain definitive answers from health professionals left them feeling unsupported which may be due to dyspraxia being labelled as a "hidden disorder" (Gibbs et al., 2007; Kirby, 2003; Novak et al., 2011; Stansell, 2007). Perhaps health professionals should begin to consider incorporating a greater sense of support base for parents and families within the tailored treatment plan of the child.

\section{Limitations}

As a result of the contentious nature surrounding the definition and diagnosis of dyspraxia, obtaining participants whose child had received an "official" diagnosis proved to be challenging. In order to combat this, the current study aimed to include fathers whose children rather presented with dyspraxia.

In terms of the demographics of the participants, including a more diverse sample of fathers as well as fathers with female children may have added other important findings to the study.

Furthermore, all children of the fathers that were included in the current study were involved within a treatment intervention or had received some form of therapeutic intervention programme prior to each interview. As a result, participants were likely to be more resilient than a father that has less financial stability or access to various health services, professionals and therapeutic intervention programmes.

\section{Recommendations}

Notwithstanding the limitations of the study, this section highlights some considerations for future research and a few practical suggestions as highlighted by fathers within the current study.

Future research would benefit from adopting a more masculinity-focused framework to determine the effect that learning disorders have on constructing and challenging more traditional gendered constructions of what it means to be a man, masculinity and what it means to be a father, fatherhood and fathering. Moreover, research should include a focus on the aspect of fathers and fathering and the impact thereof on the role of mothers and mothering and visa-versa. Through these alternative understandings of what it means to be a father and what it means to be a mother, more equal conceptualisations of these roles may emerge and more generally, what it means to be a man and what it means to be a woman as well. This is fundamental in order to begin to challenge the essentialist notions that limit what is conceptualised with each role as father and mother, man and woman. In addition, workshops should encourage a particular focus on generating open dialogues between fathers and mothers to assist in the creation of these alternative understandings.

Therapists and other health professionals should keep in mind that having a child with a learning disability can have a multifaceted impact on the family unit in its entirety. Perhaps incorporating a family systems approach would serve families better in terms of their capacity to cope and adapt to the diagnosis and the challenges faced thereof for their child. 
In addition, owing to the nature of dyspraxia and its shared genetic properties with various other comorbid disorders (autism, $\mathrm{ADHD}$, global learning difficulties, etc.), finding a relevant and all encompassing, yet appropriate support group can be challenging. The importance is to be able to find a "support without boundaries" for parents and subsequently their children. This may be due to the fact that some authors have appropriately described dyspraxia as a "hidden disorder" (Kirby, 2003; Novak et al., 2011; Stansell, 2007).

Although research has expanded to include the experiences of siblings when a child has been diagnosed with a learning disorder, within the South African context, this remains a largely under-researched area. As indicated within the current study, the importance of the sibling interaction and experience is crucial, as they offer a supportive function to parents. Furthermore, a variety of studies focus particularly on the individual experience of a family member without considering the family unit in its entirety. Future studies should seek to include the entire family as part of the understudy. Utilising a focus group design, researchers would be able to access crucial information from fathers, mothers and siblings on the family experience of having a child with a learning disability, thereby informing various treatment options and interventions.

It was suggested by some fathers that a more informal support network/forum/hub needs to be developed to better assist parents and healthcare professionals to share information and offer practical suggestions. This was indicated by one father (Participant 8, p. 13) "I think there's a, there's a wealth of information out there that people just do not have the forum really to share it ... I think a lot of people just want to speak honestly you know like I struggled with my child in this area and this is what I did with it you know. I mean my child could not go to a normal school he was chucked out of some school once or twice, this is what we did, this is what works."

This was further emphasised by the same father when discussing the knowledge that parents gain through their own lived experiences; "I mean if you think about it a lot of people actually take 2 years before they, they sort of, sort of find the right people. It would be nice to know that there's some people that you can talk to from day 1 and possibly save your child 2 years of battling and you just going sideways and not forward." Perhaps considering more practical options for parents to use in the treatment of their child at home, instead of indicating what parents should not do, rather indicating what parents can do.

\section{Conclusion}

Fathering a child that presents with dyspraxia challenges the foundation of parenting, the parental subsystem, the sibling subsystem, the spousal subsystem and more broadly the family unit holistically. Dyspraxia challenges the nature of traditional parenting as well as the notions of how traditional conceptions of fatherhood have been constructed. This study further subjugates the construction of parenting and dismantles the traditional roles of both father and mothers when rearing a child with a disability.

This study further illuminates the disconnection between conventional constructions of fatherhood in South Africa that positions fathers in a rigid and fixed role that is presented in a negative light (Conway, 2008; Makusha and Richter, 2015; Mavungu, 2013; Shefer et al., 2010). The study thus illustrates that fathers' roles are inextricably more complex, shifting between more traditional conceptions such as the provider towards the all giving and nurturing care. This in-turn disrupts the entire family structure and function as roles subsequently become more blurred rather than clearly distinct and defined.

However, it is important to indicate that although awareness has increased and traditional gendered roles have become blurred, there are many indicators that show how parents still operate from a very heteronormative male headed, male authority-based model of families. This is evident within the literature that points to the fact that a father's acceptance or rejection largely determines how the family will function (Dyson, 1997; Seligman and Darling, 2007). 


\section{References}

Al-Yagon, M. (2015), "Fathers and mothers of children with learning disabilities: links between emotional and coping resources", Learning Disability Quarterly, Vol. 38 No. 2, pp. 112-128.

American Psychiatric Association (2013), The Diagnostic and Statistical Manual of Mental Disorders, 5th ed., American Psychiatric Publishing, Washington, DC.

Baum, S. (2007), "The use of family therapy for people with learning disabilities", Advances in Mental Health and Learning Disabilities, Vol. 1 No. 2, pp. 8-13, doi: 10.1108/17530180200700014.

Becvar, D.S. (Ed.) (2013), The Handbook of Family Resilience, Springer, New York.

Berryhill, M.B., Soloski, K.L., Durtschi, J.A. and Adams, R.R. (2016), "Family process: early child emotionality, parenting stress, and couple relationship quality", Personal Relationships, Vol. 23, pp. 23-41.

Botha, F., Booysen, F. and Wouters, E. (2017), "Family functioning and socioeconomic status in South African families: a test of the social causation hypothesis", Social Indicators Research, Vol. 137 No. 2, pp. 789-811, doi: 10.1007/s11205-017-1600-x.

Bregman, O.C. and White, C.M. (Eds) (2011), Bringing Systems Thinking to Life: Expanding the Horizons for Bowen Family Systems Theory, Routledge, London.

Briesmeister, J.M. and Shaefer, C.E. (2007), Handbook of Parent Training: Helping Parents Prevent and Solve Problem Behaviours, John Wiley \& Son, New Jersey.

Clarke, V. and Braun, V. (2013), "Teaching thematic analysis: over coming challenges and developing strategies for effective learning", The Psychologist, Vol. 26 No. 2, pp. 120-123.

Colley, M. (2006), Living with Dyspraxia: A Guide for Adults with Developmental Dyspraxia, Jessica Kingsley Publishers, London.

Conway, D. (2008), "The masculine state in crisis state response to war resistance in Apartheid South Africa", Men and Masculinities, Vol. 10 No. 4, pp. 422-439.

Dyson, L.L. (1997), "Fathers and mothers of school-age children with developmental disabilities: parental stress, family functioning, and social support", American Journal of Mental Retardation, Vol. 102 No. 3, pp. 267-279.

Freedman, R.I. and Boyer, N.C. (2000), "The power to choose: support for families caring for individuals with developmental disabilities", Health and Social Work, Vol. 25, pp. 59-68.

Gaines, R., Missiuna, C., Egan, M. and McLean, J. (2008), "Educational outreach and collaborative care enhances physician's perceived knowledge about developmental coordination disorder", $B M C$ Health Services Research, Vol. 8 No. 21, doi: 10.1186/1472-6963-8-21.

Gibbs, J., Appleton, J. and Appleton, R. (2007), "Dyspraxia or developmental coordination disorder? Unravelling the enigma", Archives of Disease in Childhood, Vol. 92 No. 6, pp. 534-539.

Haefner, J. (2014), “An application of Bowen family systems theory”, Issues in Mental Health Nursing, Vol. 35, pp. 835-841.

Hastings, R.P. (2003), "Child behaviour problems and partner mental health as correlates of stress in mothers and fathers of children with Autism", Journal of Intellectual Disability Research, Vol. 47, pp. 231-237.

Haydon-Laurelut, M. (2011), "Disablement, systemic therapy and people with learning disabilities", Context, Vol. 114, pp. 7-11.

Heiman, T. (2002), "Parents of children with disabilities: resilience, coping, and future expectations", Journal of Developmental and Physical Disabilities, Vol. 14 No. 2, pp. 159-171.

Henninger, N.A. and Taylor, J.L. (2014), "Family perspectives on a successful transition to adulthood for individuals with disabilities", Intellectual and Developmental Disabilities, Vol. 52 No. 2, pp. 98-111.

Houghton, C., Casey, D., Shaw, D. and Murphy, K. (2013), "Rigour in qualitative case-study research", Nurse Researcher, Vol. 20 No. 4, pp. 12-17.
Dyspraxia and

the challenges faced by fathers 
Ingber, S. and Most, T. (2012), "Fathers' involvement in preschool programs for children with and without hearing loss", American Annals of the Deaf, Vol. 157, pp. 276-288.

Jones, J. and Passey, J. (2004), "Family adaptation, coping and resources: parents of children with developmental disabilities and behaviour problems", Journal on Developmental Disabilities, Vol. 11 No. 1, pp. 31-46.

Jongmans, M.J., Smits-Engelsman, B.C. and Shoemaker, M.M. (2003), "Consequences of comorbidity of developmental coordination disorder and learning disabilities for severity and pattern of perceptual-motor dysfunction”, Journal of Learning Disabilities, Vol. 36 No. 6, pp. 528-537.

Karande, S. and Kuril, S. (2011), "Impact of parenting practices on parent-child relationships with specific learning disability", Journal of Postgraduate Medicine, Vol. 57 No. 1, pp. 20-30.

Kaur, G. and Scior, K. (2009), "Systemic working in learning disability services: a UK wide survey", British Journal of Learning Disabilities, Vol. 37, pp. 213-220, doi: 10.1111/j.1468-3156.2009.00553.x.

Kersh, J., Hedvat, T.T., Hauser-Cram, P. and Warfield, M.E. (2006), "The contribution of marital quality to the well-being of parents of children with developmental disabilities", Journal of Intellectual Disability Research, Vol. 50 No. 12, pp. 883-893.

Kirby, A. (2003), "Dyspraxia: the hidden handicap", Journal of Occupational Psychology, Employment and Disability, Vol. 5 No. 2, pp. 45-46.

Lamb, M.E. (2004), The Role of the Father in Child Development, John Wiley \& Sons, Boston.

Lavoie, R.D. (2001), Fathers of Kids with LD, Schwab Foundation, San Francisco.

Mack, N., Woodsong, C., MacQueen, K.M., Guest, G. and Namey, E. (2005), Qualitative Research Methods: A Data Collector's Field Guide, Family Health International, North Carolina.

Makusha, T. and Richter, L. (2015), "Non-resident black fathers in South Africa", Fathering: Encyclopedia on Early Childhood Development, available at: http://www.child-encyclopedia.com/ sites/default/files/textes-experts/en/4513/non-resident-black-fathers-in-south-africa.pdf.

Malterud, K., Siersma, V.D. and Guassora, A.D. (2016), "Sample size in qualitative interview studies: guided by information power", Qualitative Health Research, Vol. 26 No. 13, pp. 1753-1760, doi: $10.1177 / 1049732315617444$.

Masiglio, W. (2008), “Understanding men's prenatal experience and the father involvement connection: assessing baby steps", Journal of Marriage and Family, Vol. 70 No. 5, pp. 1108-1113.

Mavungu, E.M. (2013), "Provider expectations and father involvement: learning from experiences of poor "absent fathers" in Gauteng, South Africa", African Sociological Review, Vol. 17 No. 1, pp. 65-78.

McMurray, S., Drysdale, J. and Jordan, G. (2009), "Motor processing difficulties: guidance for teachers in mainstream classrooms", Support for Learning, Vol. 24 No. 3, pp. 119-125.

MenCare: A Global Fatherhood Campaign (2012), What Fathers Have to Do With it: Enaging Men as Caregiving Partners, Promundo and Sonke Gender Justice Network, available at: http:// menengage.org/wp-content/uploads/2014/01/What_Fathers_Have_to_do_with_it.pdf.

Miyahara, M. and Baxter, D.G. (2011), "Children with "dyspraxia": a survey of diagnostic heterogeneity use and perceived effectiveness of interventions", Journal of Developmental and Physical Disabilities, Vol. 23, pp. 439-458.

Neale, B. and Davies, L. (2016), "Becoming a young breadwinner? The education, employment and training trajectories of young fathers", Social Policy and Society, Vol. 15 No. 1, pp. 85-98.

Novak, C., Lingam, R., Coad, J. and Emond, A. (2011), "Providing more scaffolding': parenting a child with developmental co-ordination disorder, a hidden disability", Child: Care, Health and Development, Vol. 38 No. 6, pp. 829-835.

O'Gorman, S. (2012), "Attachment theory, family system theory, and the child presenting with significant behavioural concerns", Journal of Systemic Therapies, Vol. 31 No. 3, pp. 1-16.

Patterson, J.M. (2002), “Understanding family resilience”, Journal of Clinical Psychology, Vol. 58 No. 3, pp. 233-246. 
Payne, S., Ward, G., Turner, A., Taylor, C.M. and Bark, C. (2013), "The social impact of living with developmental coordination disorder as a 13 year old”, British Journal of Occupational Therapy, Vol. 76 No. 8, pp. 362-369.

Peters, J.M., Barnett, A.L. and Henderson, S.E. (2001), "Clumsiness, Dyspraxia and Developmental Coordination Disorder: how do health and educational professionals in the UK define the terms?", Child: Care, Health and Development, Vol. 27 No. 5, pp. 399-412.

Poslawsky, I.E., Naber, F.B., Van Daalen, E. and Van Engeland, H. (2014), "Parental reaction to early diagnosis of their children's autism spectrum disorder: an exploratory study", Child Psychiatry and Human Development, Vol. 45 No. 3, pp. 294-305.

Rosenberg, J. and Wilcox, W.B. (2006), The Importance of Fathers in the Healthy Development of Children, U.S Department of Health and Human Services, Washington.

Rubin, K.H. and Chung, O.B. (2006), Parenting Beliefs, Behaviours, and Parent-Child Relations: A Cross-Cultural Perspective, Psychology Press, New York.

Saltzman, W.R., Pynoos, R.S., Lester, P., Layne, C.M. and Beardslee, W.R. (2013), "Enhancing family resilience through family narrative co-construction", Clinical Child and Family Psychology Review, Vol. 16, pp. 294-310.

Santrock, J. (2014), Life-span Development, McGraw-Hill Education, New York.

Seligman, M. and Darling, R.B. (2007), Ordinary Families, Special Children: A Systems Approach to Childhood Disability, 3rd ed., The Guilford Press, London.

Shefer, T., Stevens, G. and Clowes, L. (2010), "Men in Africa: masculinities, materiality and meaning", Journal of Psychology in Africa, Vol. 20 No. 4, pp. 511-518.

Smith-Acuna, S. (2011), Systems Theory in Action: Applications to Individual, Couples, and Family Therapy, John Wiley \& Sons, New Jersey.

Stansell, D.J. (2007), "Giving a face to a hidden disorder: the impact of dyspraxia", Teaching Exceptional Children Plus, Vol. 4 No. 1, available at: https://files.eric.ed.gov/fulltext/ EJ967468.pdf.

Steinman, K.J., Mostofsky, S.H. and Denckla, M.B. (2010), “Toward a narrower, more pragmatic view of developmental dyspraxia", Journal of Child Neurology, Vol. 25 No. 1, pp. 71-81.

Strong, B., DeVault, C. and Cohen, T.F. (2011), The Marriage and Family Experience: Intimate Relationships in a Changing Society, 11th ed., Wadsworth Cengage Learning, Belmont.

Tanaka, Y., Yoshida, A., Kawahata, N., Hashimato, R. and Obayashi, T. (1996), "Diagnostic dyspraxia: clinical characteristics responsible lesion and possible underlying mechanism", Brain, Vol. 119, pp. 859-873.

Terre Blanche, M., Durheim, K. and Painter, D. (2011), Research in Practice, UCT Press, Cape Town.

Titelman, P. (Ed.) (2014), Differentiation of Self: Bowen Family Systems Theory Perspectives, Routledge, New York.

Visagie, A. (2010), Research Methodology, Midrand Graduate Institute, Midrand.

Walsh, F. (Ed.) (2012), Normal Family Processes: Growing Diversity and Complexity, Guilford Press, New York.

Walsh, F. (2016), Strengthening Family Resilience, 3rd ed., The Guilford Press, New York.

$\mathrm{Xu}, \mathrm{Y}$. (2019), "Partnering with families of young children with disabilities in inclusive settings", in Advancing Inclusive and Special Education in the Asia-Pacific, Springer, Singapore, pp. 3-15.

Yamada, A., Kato, M., Suzuki, M., Suzuki, M., Watanabe, N., Akechi, T. and Furukawa, T.A. (2012), "Quality of life of parents raising children with pervasive developmental disorders", $B M C$ Psychiatry, Vol. 12, doi: 10.1186/1471-244X-12-119.

Zwicker, J.G., Missiuna, C., Harris, S.R. and Boyd, L.A. (2012), "Developmental coordination disorder: a review and update", European Journal of Paediatric Neurology, Vol. 16, pp. 573-581. 
About the authors

Kyle Jackson is a practicing research psychologist and registered counsellor who works as a lecturer in the department of psychology at the University of the Western Cape. His research interests include fatherhood, masculinity and children's subjective well-being. Kyle Jackson is the corresponding author and can be contacted at:kmjackson@uwc.ac.za

Michelle Andipatin is the Deputy Dean of Research in the Faculty of Community and Health Sciences at the University of the Western Cape. Her background is Psychology and she specialised in Research Psychology. Her research is in the area of women's health, high-risk reproductive health, gender issues, masculinities and qualitative research.

For instructions on how to order reprints of this article, please visit our website: www.emeraldgrouppublishing.com/licensing/reprints.htm Or contact us for further details: permissions@emeraldinsight.com 